\title{
Psychisch krank - Was nun? - Wege aus der Krise
}

\author{
Mit nahtlosen Übergängen zurück in den Alltag
}

Der folgende Artikel illustriert anhand eines Fallbeispieles, wie eine nahtlose Vernetzung in der psychosozialen Rehabilitation, ohne lange Wartezeiten und Übergänge, für Betroffene Voraussetzung ist, damit eine größtmögliche Lebensqualität und Selbstständigkeit wiedererlangt werden kann.

Herbert, 49 Jahre alt, kam mit der Diagnose rezidivierende depressive Störung auf Zuweisung vom Facharzt im Jänner 2004 in die Beschäftigungstherapie der sozialpsychiatrischen Tagesstätte Klapotetz

\section{Vorgeschichte}

Herbert ist verheiratet, hat drei beinahe erwachsene Kinder und lebt in einem eigenen Haus mit seiner Familie. Von Beruf war er bis 2001 als Tischler tätig. Im Jahre 2000 kam es zu einem ersten stationären Aufenthalt in der Psychiatrie. Damals hatte er ein Burn-Out erlebt, nachdem er mehrere depressive Phasen hinter sich hatte. Er kehrte wieder an seine Arbeitsstelle zurück. Im März 2001 beklagte er zunehmend Erschöpfungszustände, Konzentrationsstörungen und Probleme mit den Vorgesetzen in der Firma. Nach einem heftigen Streit zu Hause, schnitt er sich in die Hand und wurde stationär im LKH Psychiatrie aufgenommen. Er verlor seinen Arbeitsplatz, und Herbert bekam die Invaliditätspension zuerkannt. Herbert wurde ambulant psychosozial im Beratungszentrum des psychosozialen Dienstes Leibnitz weiter betreut.

Zu Hause hatte Herbert zwar seine „Bastlerwerkstätte“ und Arbeit in und um sein Haus, für seinen Selbstwert und seine Selbstbestätigung war dies aber langfristig zu wenig. Außerhalb seiner Kernfamilie gab es für ihn kaum soziale Kontakte.

An zwei Tagen pro Woche nahm er nun am beschäftigungstherapeutischen Angebot der TS Klapotetz teil. Vor allem in der Holzwerkstätte und der Haussanierungsgruppe beim Projekt Wohnen am Hof (PSD-Leibnitz) konnte er seine umfassenden handwerklichen Kenntnisse einbringen. Zu Beginn war sein ausgeprägter fast zwanghafter Hang zum Per-

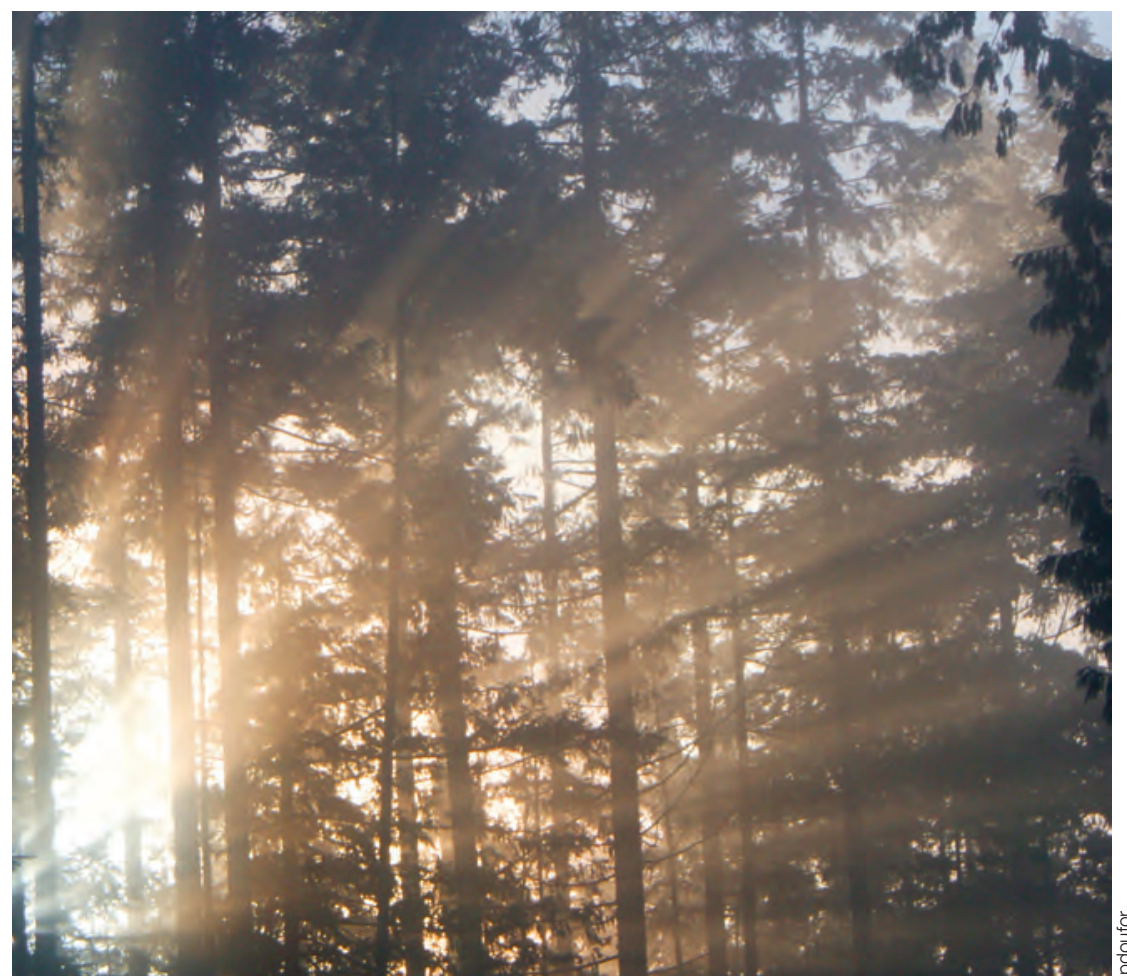

Es gibt Hoffnung auf eine Rückkehr ins „normale“ Leben.

fektionismus oft ein Hindernis bei der Fertigstellung von Produkten. Er neigte auch dazu, sich selbst zu überfordern, da er sich kaum Pausen gönnen wollte, weil sein Lebensbild von einem sehr hohen Leistungsgedanken geprägt war. Er musste innerhalb der Beschäftigungstherapie lernen, seine Energiegrenzen rechtzeitig zu erkennen, um adäquat darauf reagieren zu können. Die Möglichkeit, neue soziale zwischenmenschliche Kontakte innerhalb des Tagesstättenalltags knüpfen zu können, erlebte er als persönlich bereichernd. Gerne nahm er auch am Sport- und Freizeitprogramm teil. Seine Ehefrau berichtete, dass Herbert auch zu Hause ausgeglichener wäre und er die Teilnahme in der Tagesstätte als Arbeit bewerte. Sein Selbstwert sei gestiegen und auch fühle er sich seinen Söhnen gegenüber als „Invaliditätspensionist" nicht mehr so minderwertig. Er habe sich vorher nicht mehr wirklich als „Haushaltsvorstand“ gefühlt, was ihm aber aufgrund seines traditionell ge- färbten Weltbildes sehr wichtig war. Als im Jahr 2006 der Sozialhilfeverband Leibnitz in Zusammenarbeit mit der Bezirkshauptmannschaft Leibnitz ein neues Projekt (Arbeitsintegration von Menschen mit Beeinträchtigung vorwiegend im öffentlichen Bereich) startete, konnte Herbert als Hausmeistergehilfe in der Bezirkshauptmannschaft Leibnitz geringfügig angestellt werden. Er ist seit 2004 psychisch stabil, und es gab keinen stationären Aufenthalt mehr. Herbert fühlt sich in seiner Arbeit wohl und mit dieser Position gesellschaftlich akzeptiert. Durch die Teilnahme an der Beschäftigungstherapie hat er positive Selbstwirksamkeitserfahrungen gemacht und die Chance erhalten, beruflich wieder Fuß fassen zu können, in einem für ihn entsprechenden Rahmen.

\section{Korrespondenz:}

Mag. Helene Prack

PSD-Leibnitz

TS-Klapotetz, Sailergasse 8, 8430 Leibnitz

E-Mail: helene.prack@gfsg.at 